\title{
The effect of plant density on seed yield and quality of carrot (Daucus carota L.)
}

\author{
C.N. MERFIELD ${ }^{1}$, J.G. HAMPTON ${ }^{1}$, S.D. WRATTEN ${ }^{1}$, P. PRAPANOPPASIN ${ }^{2}$ \\ and P. YEERANSIRI ${ }^{3}$ \\ ${ }^{1}$ Bio-Protection Research Centre, P O Box 84, Lincoln University, Lincoln 7647, New Zealand \\ ${ }^{2}$ Thai Seed \& Agriculture Co. Ltd, 153 Moo-1 Tambon Muangpia, Ampur Kudjab, Udornthani 41250, Thailand \\ ${ }^{3}$ Syngenta Seeds Co. Ltd, 52/1 Moo-6 Saisri Road, Tambon Deelung, Pattananikom, Lapburi 15220, Thailand \\ hamptonj@lincoln.ac.nz
}

\begin{abstract}
The hypothesis that by increasing carrot (Daucus carota) plant density the contribution to seed yield by the primary umbels would increase, and that therefore both seed yield and seed quality would increase, was examined in two experiments in different years in Canterbury. A radial trial design provided plant densities from 2 to 84 plants $/ \mathrm{m}^{2}$ and from 4 to 100 plants $/ \mathrm{m}^{2}$ in experiments one and two respectively. Seed yield increased with increasing plant density in both experiments, and at the highest density the primary umbels contributed $90 \%$ (experiment one) and $60 \%$ (experiment two) of the seed yield. In both experiments seeds from the primary umbels had a greater thousand seed weight and higher germination than those from the other order umbels, and for the second experiment they also had higher seed vigour. The quality of seeds from the primary umbels was consistently higher than that of seeds from the secondary umbels across all plant densities, and for the latter, both germination and seed vigour declined as plant density increased. These results therefore support the hypothesis, and densities higher than the 20 plants $/ \mathrm{m}^{2}$ currently used commercially have the potential to increase both seed yield and quality.
\end{abstract}

Keywords: seed production, primary umbels, germination, vigour, plants $/ \mathrm{m}^{2}$

\section{Introduction}

The relationships between carrot (Daucus carota L.) plant density, seed yield and seed quality have been previously investigated (Gray 1981; Gray et al. 1983; Malik et al. 1983; Noland et al. 1988; Oliva et al. 1988). Gray (1979) and Gray and Steckel (1983a) demonstrated that seed from primary umbels was of superior quality (germination and thousand seed weight) to seed from lower order umbels, and Jacobsohn and Globerson (1980) and Gray (1981) proposed using high plant densities for carrot seed production because the contribution to seed yield from primary umbels would increase as plant density increased. This was demonstrated in later studies (Gray et al. 1983; Gray \& Steckel 1983a) where, as plant density was increased from 10 to 80 plants $/ \mathrm{m}^{2}$, the proportion of seed produced on the primary umbels increased from $25 \%$ to $62 \%$, seed yield was increased by approximately $50 \%$, and heavier seeds were produced from the primary umbels.

New Zealand supplies approximately $40 \%$ of the world's carrot seed (D. Storrier pers. comm. 2008), primarily under contracts to European seed houses. This production is based in Canterbury. The seed to seed production method (George 1999) is used, and plant populations are commonly around 20 plants $/ \mathrm{m}^{2}$ (D. Storrier pers. comm. 2008)). Whether these populations are optimal for New Zealand conditions has not previously been reported. The objectives for this work were to determine the effect of plant density on (i) carrot seed yield and (ii) carrot seed quality including seed vigour (ISTA 2008), a seed quality component not assessed in any of the previous studies. 


\section{Methods}

Two experiments were conducted, the first (experiment 1) in the 1999/2000 season under a conventional production system, and the second (experiment 2) in the 2004/2005 season under an organic production system (Merfield 2006). A $4 \frac{1}{2^{\circ}}$ radial trial design (Nelder 1962; Bleasdale 1967) was used for both experiments.

\section{Experiment 1}

The experiment was conducted within a commercial carrot seed crop at Dorie, midCanterbury on a Templeton shallow silt loam soil. In the previous three years the paddock had been in pasture, sweet corn and processed peas. Following conventional cultivation, the commercial crop was sown on 2 February 1999 using a ratio of two male to six female rows. The male and female lines were unknown Bejo Zaden B.V. parents. In August 1999 the trial area (which had not been sown) was rotary hoed and male and female stecklings from the crop were transplanted using the same ratio into a half-radial design which had 25 arcs giving plant densities ranging from 2 to 84 plants $/ \mathrm{m}^{2}$. The inner and outermost arcs and the outside radii of the female parent line which grew next to the male parent line were guard rows. Subsequent crop husbandry, including weed and disease control, fertiliser and irrigation were the same as for the commercial crop.

Seed moisture (ISTA 2008) was monitored during seed development, and hand harvesting took place when the moisture content of seeds from the primary umbels was $10.5 \%$ (24 March 2000). Five randomly selected female plants were removed from each plant density (with the exception of the guard rows), and umbels from each order (i.e., primary to quaternary) were removed, counted, and kept separately. The umbels were then hand threshed and cleaned using a Westrup (Westrup A/S, Slagelse, Denmark) seed cleaner which had a scalping screen of $3.0 \mathrm{~mm}$ round, top screen of $1.75 \mathrm{~mm}$ slotted, and bottom screen of $0.7 \mathrm{~mm}$ slotted. Cleaning was completed by passing the seeds through an indented cylinder $(3.0 \mathrm{~mm}$ indent). Seeds were then kept in sealed containers at $5^{\circ} \mathrm{C}$ until quality testing.

\section{Experiment 2}

Experiment 2 was conducted at Lincoln University on a Wakanui silt loam soil at a site which had previously been in pasture for five years. A full circle radial design with 18 arcs was used to produce plant densities from 4 to 100 plants $/ \mathrm{m}^{2}$. There were six replicates with each block of six female radii treated as a replicate. On 4 March 2004, 36day-old stecklings (unknown Bejo Zaden B.V. male and female lines) were transplanted using the same 2:6 ratio as for the first experiment. The trial was managed according to BioGro organic standards (Anon 2001), hand weeded, and no fertilisers were applied. Seed harvest (26 March 2005) and cleaning were as described for experiment 1 , except that for logistical reasons, only data from densities of 5,11 , 20,55 and 82 plants $/ \mathrm{m}^{2}$ were collected.

\section{Seed quality assessment}

Seeds from each plant density were bulked together by umbel order for the calculation of seed yield. Germination and thousand seed weight were then determined following internationally agreed methodology (ISTA 2008). Seed vigour was determined using the accelerated ageing test described for soybean (ISTA 2008), whereby seeds were aged at $41^{\circ} \mathrm{C}$ for $72 \mathrm{~h}$ at $96 \% \mathrm{RH}$ before having their post-ageing germination determined. Seed vigour data are presented only for primary and secondary umbels, as there was insufficient seed from lower order umbels.

\section{Data analysis}

Results from experiment one, except for vigour, were analysed by fitting curves using Microsoft $^{\circledR} \quad$ Excel $^{\circledR} 2002$ SP3. Linear, logarithmic, polynomial, power and 
exponential curves were fitted with the curve having the highest $\mathrm{R}^{2}$ selected. For experiment two and for the vigour data from experiment one, data were analysed by ANOVA.

\section{Results}

\section{Experiment 1}

Seed yield increased with increasing plant density from $5.2 \mathrm{~g} / \mathrm{m}^{2}$ to $21.9 \mathrm{~g} / \mathrm{m}^{2}$ (Figure 1). Quaternary umbels did not produce seeds, and tertiary umbels made a very minor contribution to seed yield only at the lowest plant densities (Figure 1). The yield from secondary umbels declined with increasing plant density while that of the primary umbels increased (Figure 1). At 20 plants $/ \mathrm{m}^{2}$, the primary umbels contributed approximately $60 \%$ of the seed yield c.f. $40 \%$ from the secondary umbels, but at 70 plants $/ \mathrm{m}^{2}$, the contribution from the primary umbels had increased to nearly $90 \%$ (Figure 2).

The effects of plant density on seed quality were more variable. While seeds from primary umbels were heavier than seeds from secondary or tertiary umbels (Figure 3a), thousand seed weight initially declined as plant density increased, but then increased again at higher plant densities (Figure 3a). The germination of seed from the primary umbels was $86 \%$ or greater for all plant densities, but tended to decrease with increasing plant density for seeds from the secondary umbels (Figure 3b). Seed vigour was determined from only five plant densities; for seeds from secondary umbels seed vigour decreased as plant density increased, but for seeds from primary umbels, seed vigour declined as plant density increased to 28 plants $/ \mathrm{m}^{2}$, but then increased at 54 plants $/ \mathrm{m}^{2}$ (Figure 3c).

\section{Experiment 2}

Increasing plant density significantly increased seed yield, from $124 \mathrm{~g} / \mathrm{m}^{2}$ at 5 plants $/ \mathrm{m}^{2}$ to $266 \mathrm{~g} / \mathrm{m}^{2}$ at 82 plants $/ \mathrm{m}^{2}$ (Table 1). This increase was accounted for by an increase in seed yield from the primary umbels, as yields from the secondary umbels did not differ with increasing plant density (Table 1). At 20 plants $/ \mathrm{m}^{2}$, the secondary umbels contributed $76 \%$ of the seed yield, at 55 plants $/ \mathrm{m}^{2}$ the contribution from both primary and secondary umbels was around $50 \%$ each, and at 82 plants $/ \mathrm{m}^{2}$ the primary umbels were contributing $60 \%$.

The effects of increasing plant density on thousand seed weight were very small (Table 2). Seeds from primary umbels were heavier than those from secondary umbels, but there were no clear effects of plant density for either umbel order. Germination was greater in seeds from the primary umbels at all densities except the lowest (Table 2), did not differ among densities for seeds from the primary umbels, but decreased at the three highest plant densities for seeds from the secondary umbels (Table 2). Seed vigour differences were not significant among the densities for seeds from the primary umbels, but seed vigour was reduced in seeds from the secondary umbels at the highest density (Table 2). 


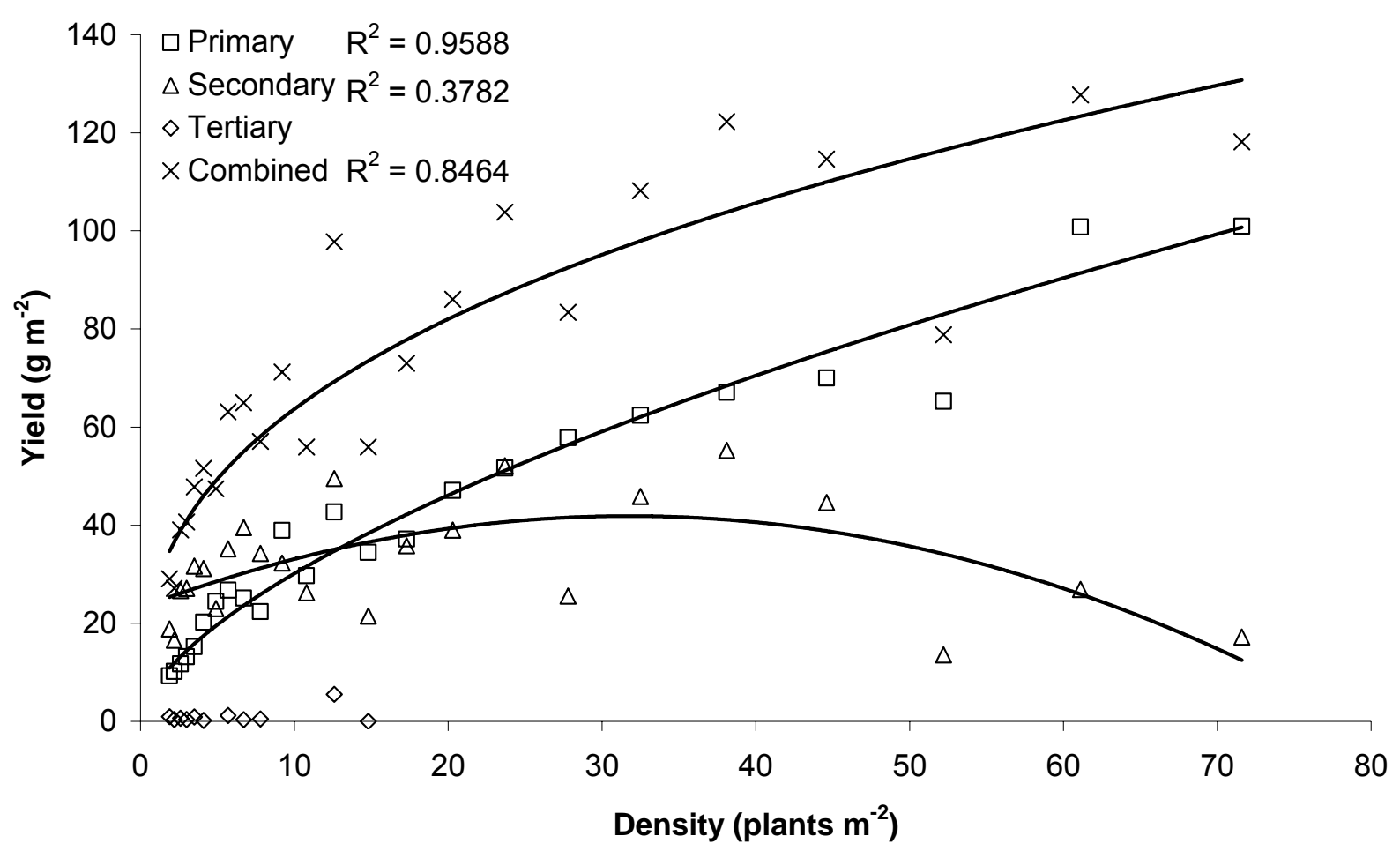

Figure 1 Effect of plant density on carrot seed yield in the 1999/2000 season.

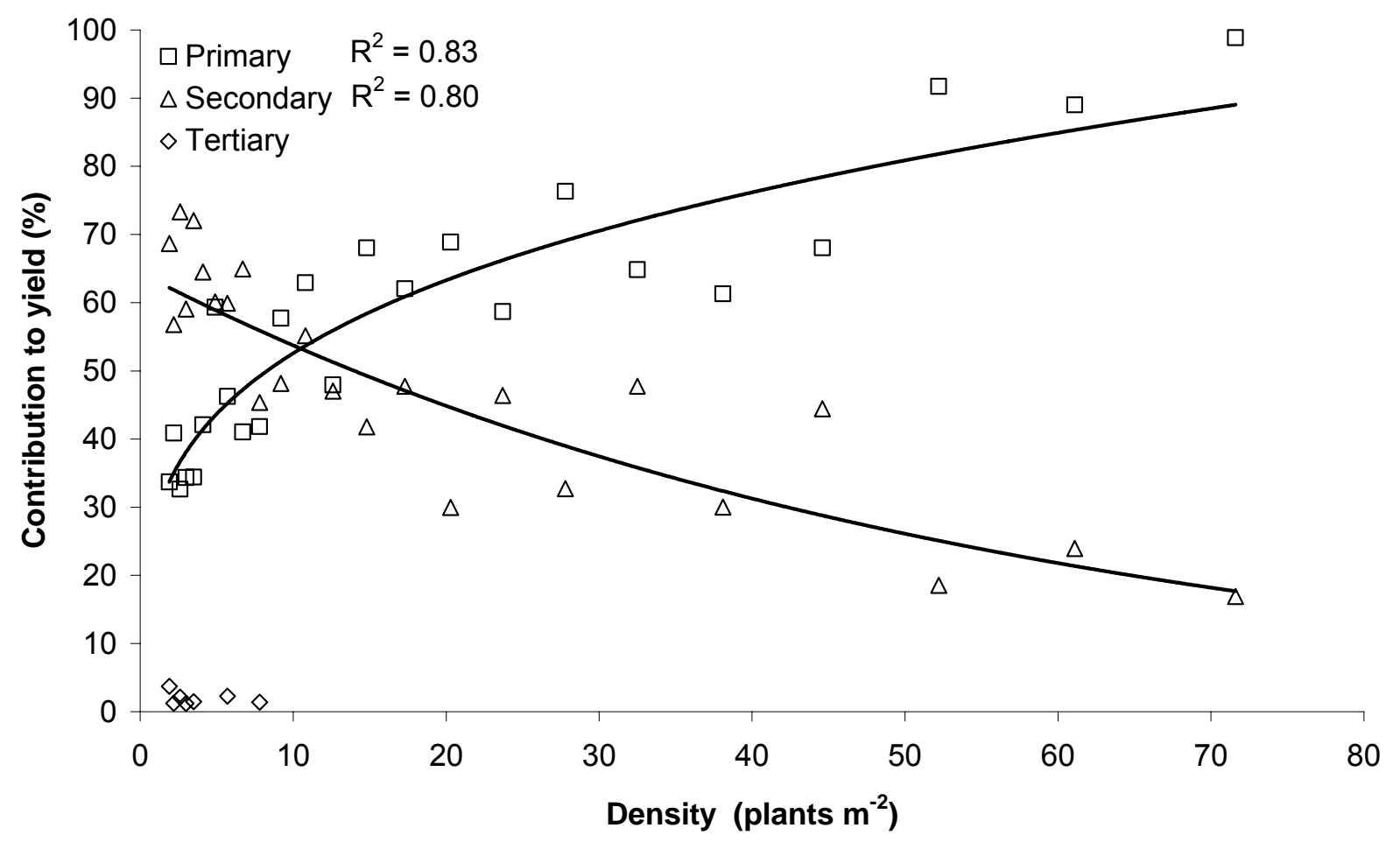

Figure 2 Effect of plant density on the proportional contribution of the umbels to carrot seed yield in the 1999/2000 season. 

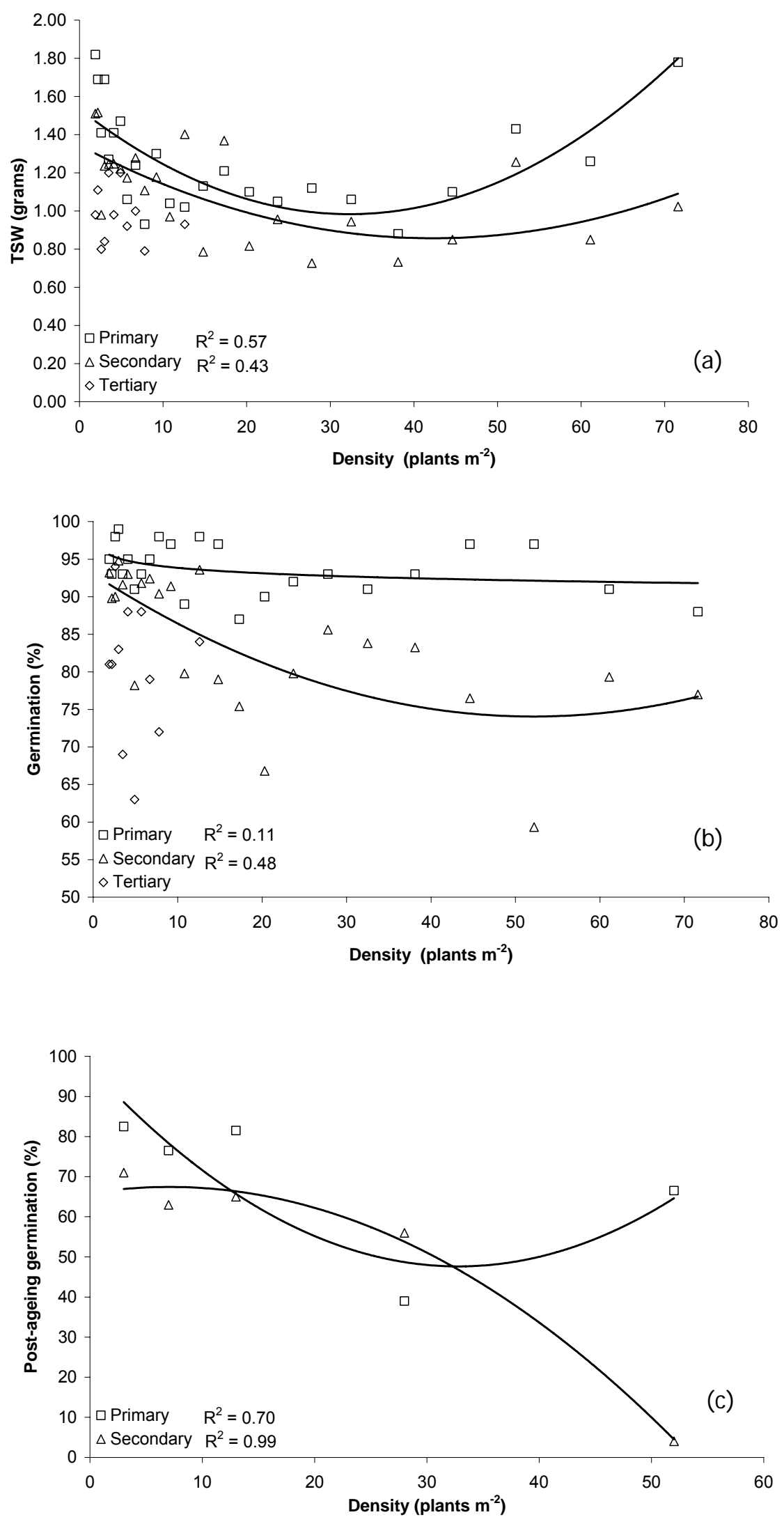

Figure 3 Effect of plant density on carrot seed quality in the 1999/2000 season: (a) thousand seed weight, (b) germination and (c) seed vigour. 
Table 1 Effect of plant density on carrot seed yield $\left(\mathrm{g} / \mathrm{m}^{2}\right)$ in the 2004/2005 season (untransformed and $\log _{e}(x+1)$ transformed data).

\begin{tabular}{lccccccc}
\hline & \multicolumn{7}{c}{ Plant density $\left(\right.$ plants $\left./ \mathrm{m}^{2}\right)$} \\
& 5 & 11 & 20 & 55 & 82 & p value & LSD P $<0.05$ \\
\hline Total & 124 & 186 & 164 & 221 & 266 & & \\
Total $(\log )$ & 4.8 & 5.2 & 5.1 & 5.3 & 5.5 & 0.017 & 0.42 \\
Primary umbel & 15 & 27 & 38 & 104 & 155 & & \\
Primary umbel $(\log )$ & 2.7 & 3.3 & 3.6 & 4.6 & 5.0 & $<0.001$ & 0.32 \\
Secondary umbel & 97 & 143 & 125 & 117 & 111 & & \\
Secondary umbel $(\log )$ & 4.5 & 4.9 & 4.8 & 4.5 & 4.5 & 0.569 & 0.70 \\
Tertiary umbel & 12 & 16 & 2 & - & - & & \\
Tertiary umbel $(\log )$ & 2.3 & 2.7 & 0.7 & - & - & 0.011 & 1.20 \\
\hline
\end{tabular}

${ }^{1}$ insufficient seed for analysis

Table 2 Effect of plant density and umbel order on carrot seed quality in the 2004/2005 season.

\begin{tabular}{llccccccc}
\hline \multirow{2}{*}{ Quality component } & Umbel & \multicolumn{7}{c}{ Plant density (plants $\left./ \mathrm{m}^{2}\right)$} \\
& order & 5 & 11 & 20 & 55 & 82 & $\mathrm{p}$ value & LSD \\
& Primary & 1.3 & 1.4 & 1.5 & 1.2 & 1.2 & 0.013 & 0.19 \\
Thousand seed weight (g) & Secondary & 1.0 & 1.1 & 1.0 & 0.9 & 0.8 & 0.002 & 0.11 \\
& Tertiary & 0.9 & 1.0 & 1.0 & $-{ }^{1}$ & - & 0.082 & 0.14 \\
& & & & & & & & \\
Germination (\%) & Primary & 91 & 93 & 95 & 94 & 94 & 0.661 & 5.5 \\
& Secondary & 94 & 89 & 84 & 83 & 80 & 0.010 & 7.6 \\
& Tertiary & 78 & 78 & 78 & - & - & 0.995 & 21.7 \\
& & & & & & & & \\
Post-AA ${ }^{2}$ germination (\%) & Primary & 79 & 75 & 83 & 87 & 84 & 0.100 & 9.3 \\
& Secondary & 75 & 78 & 73 & 75 & 63 & 0.083 & 10.8 \\
\hline
\end{tabular}

insufficient seed for testing

${ }^{2}$ accelerated ageing vigour test

\section{Discussion}

The two experiments resulted in some similar and some contrasting results. For both, increasing plant density increased seed yield, the increase being linear in the second experiment, similar to the response reported by Gray (1981) and Noland et al. (1988), and tending to plateau in the first experiment, similar to the response reported by Hawthorn (1952) and Grey and Steckel (1983b). However the umbel order contribution to yield as plant density increased differed markedly between the two experiments. In experiment 1 , the primary umbels contributed around $60 \%$ of the total yield at 20 plants $/ \mathrm{m}^{2}$, and this increased to $90 \%$ at the highest plant density used. In contrast in experiment 2, at 20 plants $/ \mathrm{m}^{2}$ the primary umbels contributed around $20 \%$ of the total yield, and this increased to only $60 \%$ at the highest plant density. This response can be explained by differences in parent lines - although both had upright growth habits and similar numbers of secondary umbels $(9$ per plant at 20 plants $/ \mathrm{m}^{2}$ and 4-5 per plant at $75-82$ plants $/ \mathrm{m}^{2}$ ), the number of seeds per umbel differed. At the highest density, primary and 
secondary umbels in experiment 1 contained around 750 and 200 seeds respectively, while in experiment 2 the corresponding numbers were approximately 1,500 and 1,750 seeds per umbel. Why the female parent line used in experiment 2 supported more seeds per umbel through to maturity at high plant density is not known, but possible reasons include:

1. umbel size, and hence the number of flowers per umbel available to be pollinated, can differ markedly among parent lines (J. Townshend pers. comm. 2008)

2. male parent lines differ in their pollen potential, which is the amount of pollen produced and the time at which it is available. Male sterile lines for example are considered to be less attractive to pollinators because of their reduced nectaries (Quiros 2006). The male parent lines used in the two experiments may have differed in their pollen potential

3. pollination may have been more efficient in the second experiment; two beehives were placed $30 \mathrm{~m}$ from the trial site and there were no adjacent flowering crops (Merfield 2006). In comparison, the experiment 1 site was within a commercial carrot crop, and although six beehives/ha were used (J. Evans pers. comm. 2000), it is probable that adjacent pollen sources were more attractive to bees than carrot pollen. Pollen trappings in hives placed in carrot seed crops from 24 December 2007 until 21 January 2008 at four sites in mid-Canterbury showed that the percentage of carrot pollen in the total pollen load per trap was never more than $20 \%$, and at one site was less than $1 \%(\mathrm{~J}$. Townshend pers. comm. 2008).

4. the calculated seed numbers per umbel are not necessarily the same as the number of seeds originally produced, in that any very small seeds would have been discarded during the cleaning process. It is possible that at harvest, some seeds from the secondary umbels in experiment 1 were either small because of a resource limitation and/or were not as mature as those from secondary umbels in experiment 2 , with the result that these small/immature seeds were removed during cleaning.

The seed yields at a population of 20 plants $/ \mathrm{m}^{2}$ were approximately $80 \mathrm{~g} / \mathrm{m}^{2}$ in experiment 1 and $164 \mathrm{~g} / \mathrm{m}^{2}$ in experiment 2 . At 75 plants $/ \mathrm{m}^{2}$ in experiment 1 , seed yield was $110 \mathrm{~g} / \mathrm{m}^{2}$ (a $38 \%$ increase), and at 82 plants $/ \mathrm{m}^{2}$ in experiment 2 , seed yield was $266 \mathrm{~g} / \mathrm{m}^{2}$ (a $62 \%$ increase). These results suggest that Gray's (1981) conclusion that plant densities used for carrot seed production are too low was correct, and that increasing plant density above the 20 plants $/ \mathrm{m}^{2}$ currently in use would increase seed yields.

In both experiments, seeds from the primary umbels had a greater thousand seed weight and higher germination than those from the other order umbels, and for the second experiment they also had higher vigour at populations of 20 plants $/ \mathrm{m}^{2}$ or higher. The quality of seeds from the primary umbels was consistently higher than that of seeds from the secondary umbels across all plant densities for both experiments, and these results are therefore similar to those previously reported by Jacobsohn and Globerson (1980) and Grey et al. (1983). The hypothesis that increasing plant density will also increase seed quality because of the greater proportion of primary umbels contributing to the seed yield is therefore supported. However the seed vigour response to increasing plant density requires further investigation. In both experiments, the vigour of seeds from the secondary umbels decreased with increasing plant density, the response being particularly severe in experiment 1. For seeds from primary umbels, seed vigour remained high at densities of 20 plants $/ \mathrm{m}^{2}$ and higher in experiment 2 , but tended to decline with increasing plant density in experiment 1 . Castillo et al. (1993) and Rahman et al. (2005) have previously reported reduced seed vigour with increasing plant density in garden pea (Pisum sativum L.) and soybean 
(Glycine $\max (\mathrm{L}$.$) Merrill) respectively, the$ reason for this is yet to be elucidated.

In conclusion, while the experimental evidence supports Gray's (1981) hypothesis, i.e., that plant densities greater than 20 plants $/ \mathrm{m}^{2}$ should be used for carrot seed production, in practice this is unlikely to happen in New Zealand. Bejo Zaden B.V., the largest global producer of carrot seed, have chosen 20 plants $/ \mathrm{m}^{2}$ as their preferred plant density because of fungal problems (particularly from Alternaria spp.) which develop at higher densities and reduce both seed yield and quality (F. van de Crommert pers. comm. 2006).

\section{Acknowledgments}

John Evans (Tregynon Farm, Dorie) and Ivan Barnett (Biological Husbandry Unit, Lincoln University) for land, assistance with crop management and use of equipment. Midlands Seed Ltd, Ashburton for supply of seed, technical advice and financial support for C.N. Merfield. Kasetsart University and UMAP for scholarship support for P. Prapanoppasin and P. Yeeransiri. Alison Lister, Andrew McLachlan, Richard Sedcole and James Ross, Lincoln University for statistical advice. Staff of the New Zealand Seed Technology Institute/AsureQuality New Zealand seed testing laboratory for assistance with seed analysis.

\section{References}

Anon. 2001. Bio-Gro New Zealand organic standards. NZ Biological Producers \& Consumers Council, Wellington, New Zealand.

Bleasdale, J.K.A. 1967. Systematic designs for spacing experiments. Experimental Agriculture 3: 73-85.

Castillo, A.G.; Hampton, J.G; Coolbear, P. 1993. Effect of population density on within canopy environment and seed vigour in garden pea (Pisum sativum L.). Proceedings of the Agronomy Society of New Zealand 23: 99-106.
George, R.A.T. 1999. Vegetable seed production. $2^{\text {nd }}$ Edition. $\mathrm{CAB}$ International, Wallingford, Untied Kingdom. 328 pp.

Gray, D. 1979. The germination response to temperature of carrot seed from different umbels and time of harvest of the seed crop. Seed Science and Technology 7: 169-178.

Gray, D. 1981. Are the plant densities currently used for carrot seed production too low? Acta Horticulturae 111: 159-165.

Gray, D.; Steckel, J.R.A. 1983a. Seed quality in carrots: the effect of seed crop plant density, harvest date and seed grading on seed and seedling variability. The Journal of Horticultural Science 58: 393-401.

Gray, D.; Steckel, J.R.A. 1983b. Some effects of umbel order and harvest date on carrot seed variability and seedling performance. The Journal of Horticultural Science 58: 73-82.

Gray, D.; Steckel, J.R.A.; Ward, J.A. 1983. Studies on carrot seed production: effect of plant density on yield and components of yield. The Journal of Horticultural Science 58: 83-90.

Hawthorn, L.R. 1952. Interrelations of soil moisture, nitrogen, and spacing in carrot seed production. Proceedings of the American Society of Horticultural Science 60: 321-326.

ISTA 2008. International rules for seed testing. International Seed Testing Association, Bassersdorf, Switzerland.

Jacobsohn, R.; Globerson, D. 1980. Daucus carota (carrot) seed quality: I. Effects of seed size on germination, emergence and plant growth under subtropical conditions. II. The importance of the primary umbel in carrot-seed production. pp. 637-646. In Seed Production. Ed. Hebblethwaite, P.D. Butterworths, London, United Kingdom. 
Malik, Y.S.; Singh, K.P.; Yadav, P.S. 1983. Effect of spacings and number of umbels on yield and quality of seed in carrot (Daucus carota L.). Seed Research 11: 63-67.

Merfield, C.N. 2006. Organic F1 hybrid carrot (Daucus carota L.) seed production: the effect of crop density on seed yield and quality, thermal weeding and fungal pathogen management. Unpublished $\mathrm{PhD}$ Thesis, Lincoln University, Canterbury, New Zealand. 164 pp.

Nelder, J.A. 1962. New kinds of systematic designs for spacing experiments. Biometrics 18: 283-307.

Noland, T.L.; Maguire, J.D.; Oliva, R.N.; Bradford, K.J.; Nelson, J.L.; Grabe,
D.; Currans, S. 1988. Effect of plant density on carrot seed yield and quality under seed-to-seed production systems in California, Oregon and Washington. Journal of Applied Seed Production 6: 36-43.

Oliva, R.N.; Tissaoui, T.; Bradford, K.J. 1988. Relationships of plant density and harvest index to seed yield and quality in carrot. Journal of the American Society for Horticultural Science 113: 532-537.

Rahman, M.M.; Mwakangwale, M.G.; Hampton, J.G.; Hill, M.J. 2005. Plant density affects soybean seed quality. Seed Science and Technology 33: 521-525. 